\title{
Audit in child and adolescent psychiatry
}

\author{
A R Nicol
}

A statement of the aims of a child and adolescent service must be the starting point of any discussion of audit. They will be some combination of the following:

(1) Provide a service to children with emotional and behavioural, interpersonal, and developmental difficulties and their families.

(2) Offer a support, consultation, and a liaison service to other health, educational, and social service agencies in relation to children and their families.

(3) Function as a centre for teaching of students from medical, psychology, social work, nursing, and allied disciplines.

(4) Be a centre for innovation and research.

The first thing, therefore is to state the emphasis with which each of these four components is being offered. Teaching and research, for example, will be offered principally, but not exclusively by teaching hospital departments. Each aim carries its problems in audit.

Audit activity can be classified into three stages:

(1) Input: personnel and equipment on the one hand and patients and their problems or diagnoses on the other.

(2) Process: here the process of assessment, treatment, and management should be described.

(3) Outcome: this is the full appraisal of the results of assessment, treatment, and management.

The Royal College of Psychiatrists has recommended the use of clinical rather than medical audit. ${ }^{1}$ As in nearly every branch of medicine and surgery, the service is offered by a multidisciplinary team, not just medical people. It is not helpful to try and split off a separate medical component except in the context of the study of a whole service. For this reason the comments in this article should be seen as applying, for the most part, to the child psychiatric team, rather than medically qualified staff alone.

\section{Problems}

(A) FINITE RESOURCES

In a recent publication on resource needs in child psychiatry the following areas of increased work were identified: marital breakdown (the divorce rate has almost doubled in 15 years); sexual abuse (an explosion in referrals recently); forensic work (the child and adolescent psychiatrist is spending more and more time in court, mainly on child care work); and teaching undergraduates and postgraduates, medical, and non-medical staff as skills and concepts developed by child psychiatrists and their colleagues are now seen as essential across a wide band of child care practice. ${ }^{2}$ Also more time is needed for treatment, which is now more effective, and liaison work is on the increase in a variety of medical settings because modern paediatric interventions (neonatology, oncology, etc) are stressful to child, family, and staff. Children's homes have closed, resulting in many more requests for advice on management of children in the community. The list goes on, but the resources are finite, so managers are right to ask questions about how resources should be deployed.

\section{(B) THE MARKET PHILOSOPHY}

The government's solution is market forces. In this internal market measures of cost and volume will rule all unless we fight for an alternative with great vigour. Monetarist medicine has proved disastrous for health services in general in the United States ${ }^{3}$ and will do so here, particularly in those specialties that elude neat short term packaging. These will include specialties interested in life span development and childcare such as child and adolescent psychiatry, community and developmental paediatrics, and preventive child health. Returning to our stages, the input stage can be costed and indeed monetary cost is an ultimate, though not the only important summary of input. It is how this financial input is deployed in terms of skill and equipment that is crucial. Process is the domain of quality assurance, the measurement of which is difficult but of great importance. The most important point, however, is that the processes that should be developed, and monitored, must be determined by our third stage which is the one of supreme importance. Without this output stage, audit is meaningless. It is not satisfactory to substitute valid outcome measures with a measure of cost. This means that monetary arguments must be powerfully countered by concepts and supporting data which measure the output of the service. I will return to this theme.

\section{Input}

(A) DIAGNOSTIC GROUPS

In common with the rest of medicine child disorders can be grouped by diagnosis. The main 
system in use in the UK was the International Classification of Diseases (ICD-9) which was introduced in 1978 and which is just being replaced by ICD-10. ${ }^{4} \mathrm{~A}$ major contribution has also been made by the American Diagnostic and Statistical Manual (DSM-111R) system. ${ }^{5}$ These schemes have contributed to a common language for child psychiatry and have helped to bring major conceptual advances into clinical practice. Two of these advances are so important that they merit mention here, although there are many more. The most fundamental is that diagnosis should be based on observable or reported data rather than concepts. Thus anxiety can be observed and reported by the child, while the 'oedipus complex' or the 'family system' are concepts, not empirical data. The second advance was the introduction in ICD-9 of the multiaxial approach to classification. This allows a series of statements about the child's situation-that is, as well as the psychiatric problem, their overall development, any developmental disorder, any medical condition, and the psychosocial situation can be coded. This means that links can be recognised, for example between child abuse (axis 5) and unsocialised disturbance of conduct (axis 1) or asthma (axis 4) and emotional disorder (axis 1). Such a common language is essential for audit, but uncritical adoption would be a mistake as diagnosis is but one reflection of the work required in assessment, treatment, and management in determining cost and outcome. A recent small study found that diagnosis does not predict of the amount of professional time needed on a case. Research is needed to find out if there is any way of predicting workload.

(B) RESOURCES AVAILABLE TO A SERVICE: THE DISTRICT PROFILE

It is very important to remember that the audit process cuts both ways. There is precious little point in a district employing consultants if they are not given the tools to do the job. In child psychiatry this has a whole range of implications that it has sometimes been difficult for managers to grasp.

\section{The multidisciplinary team}

There has been a tendency to have several separate services operated by, for example, child psychiatrists and clinical psychologists all operating independently or even in competition, with overlapping skills and often with a considerable degree of professional isolation. This problem figured in the Cleveland tragedy. It is important that different medical and nonmedical workers with children and families can call on each other's skills easily. With the increase in bureaucratic control and the line management principle in education and social services departments, and to some extent changes in the professional identities of nonmedical disciplines, it has become harder to develop and manage multidisciplinary teams. Useful questions can be asked at district level about how well services are organised in providing a service for children. In a recent study (AR
Nicol, unpublished observations) it was found that while $94 \%$ of child psychiatrists worked in a multidisciplinary team, only half of these contained a clinical psychologist and only $21 \%$ contained an educational psychologist. Multidisciplinary teams are not self evidently the right way to organise a service, although there are strong arguments for them. Their working in itself could be audited-for example, how much time do team members spend trying to resolve, or avoid, interdisciplinary problems rather than getting on with their work?

\section{Network of services}

The second of our aims, the provision of consultation and support requires that, within a district, child psychiatrists be involved in a range of agencies. These could include a child development centre, special schools, children's homes, and so on. It is essential that this contribution is recognised by the appropriate involvement in joint planning and, for example, representation on the area child protection committee. This is another way in which the effectiveness of a service could be monitored.

\section{Process}

\section{(A) CASE SUPERVISION}

Historically, this is the earliest activity that could be called audit. The interview is the main clinical technique used in child psychiatry, both in diagnosis and treatment. What goes on in interviews is therefore of great importance. Training supervision should be divided between discussion of case management on the one hand and detailed dissection of interviewing style on the other. In earlier times, supervision was by an account of the therapy session written out afterwards and then reported to the supervisor. Numerous studies have shown that this form of supervision is unsatisfactory, for example in a study of medical students it was found that $54 \%$ of the themes identified in a videotape of an interview were not reported at a memorised account. ${ }^{6}$ Supervision is often thought of as something that occurs in training only, but this should not be the case, as it is a most sensitive form of quality control. More recently, with the advent of family therapy the idea of live supervision has become more widespread and acceptable. Here the direction of the therapeutic interview can be influenced as it progresses, but we must ensure that senior colleagues are prepared to be audited in this way as well as trainees. Though it is important that constrictive procedures are avoided, there is room for the development of interview measures of quality, for example simple ways of classifying the aim of the interview and how well it succeeds in this stated aim.

\section{(B) PEER REVIEW}

In child psychiatry peer review is now becoming common, based characteristically on regional groups that have existed for some time. This can be by routine review of case notes and discussion of clinical practice. The most tangible 
outcome has been critique of the quality of record keeping. ${ }^{7}$

(c) HOW PROFESSIONAL TIME IS SPENT

A common perception is that consultants spend most of their time in committees. A diary study of 50 consultant child and adolescent psychiatrists gave a more optimistic picture. ${ }^{8}$ Fifty two per cent of the sample were spending between 20 and 30 hours per week in clinical work whereas $42 \%$ of the sample (the mode) were spending between five and 10 hours per week in management: more than enough some might say. There was also substantial time investment in teaching, consultation, and travel. Diary methods such as this, if kept simple, are extremely easy and give a clear overview of time budgetting.

(D) LINKS AND COOPERATION WITH OTHER CHILD CARE AGENCIES

Managment of child psychiatric disorder demands cooperation with a network of children's services, not least the child's school. The quality of communication and cooperation with such agencies could be an important indicator of quality of the service.

(E) EDUCATION: SPECIALIST TRAINING

Under the auspices of the Joint Committee for Higher Psychiatric Training ${ }^{9}$ child and adolescent psychiatrists have worked hard to develop high grade training programmes, particularly for senior registrars, this being the level at which specialist training occurs. Four years of training are recommended during which the trainee must be attached to several trainers and have a wide and prescribed variety of experience with a range of different disorders, both inpatient and outpatient, using the full range of treatments available. Log books of experience are kept in many schemes and regular supervision is compulsory. Other essentials are court work and experience of child abuse, children in care, and children with learning difficulties. The trainee must undertake research or a formal clinical innovation. The schemes are rigorously inspected and there have been disqualifications of schemes that haven't achieved the high standards expected. A district that appoints a child psychiatrist knows, nowadays, what skills they should be getting for their money.

(F) THE CHILD PSYCHIATRIST AS A TEACHER Training of other medical staff at undergraduate and postgraduate level is a field that could be usefully expanded. The Association of University Teachers of Psychiatry has produced a statement of the topics in child psychiatry that may be usefully included in an undergraduate curiculum. An auditing process could help determine which of these approaches should be developed and which are less valuable. ${ }^{10}$

THE KORNER MINIMUM DATA SET

The Korner recommendations for management information for the NHS carries many problems for child and adolescent psychiatrists both as members of multidisciplinary teams and as consultants. ${ }^{11}$ The team problem arises because the work of non-medical colleagues is measured entirely differently than that of medical staff. Clinical psychology, for example, is covered in a quite separate report. This makes the appraisal of collaborative work impossible. As consultants, the child psychiatrist shares problems with any specialist who practices substantially in the community for the following reasons.

(1) Korner focuses on general practitioners as a referral source, yet child and adolescent psychiatry serves the community best if referrals are taken from a variety of sources.

(2) Korner takes the referral letter as the measure of a case. Child and adolescent psychiatrists often see several members of a family and indeed others in the child's social network.

(3) Most important of all, the child and adolescent psychiatrist's work often consists of consultation with other professionals rather than direct with the patients. This mode of practice is specifically recommended by the Court report. ${ }^{12}$

\section{PERFORMANCE INDICATORS}

These are measures of quantity of work and have been developed by the Department of Health with the aim of identifying services who are statistical outliers which can then be studied more carefully. Our position as child psychiatrists is that better quality information on which to run the NHS is an urgent necessity; however it is dangerous to collect misleading information. The fact that all performance indicators are based on the Korner data makes them almost valueless for the reasons given above.

\section{Assessment of outcome}

This most important of activities can be discussed under two headings:

(A) RESEARCH ON THE EFFECTIVENESS OF TREATMENT IN GENERAL

The first point to make here is that this cannot be done by monitoring of everyday clinical activity. It needs high quality and adequately funded research. One of the tests of the government's vision and sincerity in the audit enterprise will be the degree to which this is understood. The question 'is child psychiatry effective?' is as nonsensical as asking if paediatrics is effective. Yet it has been seriously posed. ${ }^{13}$ The problem has to be broken down into small testable hypotheses. Evaluation research into the assessment and treatment of children's psychological disorders has got off to a start, but far to slowly. Most intervention in child psychiatry comes under the heading of psychotherapy of one sort or another and although this is a field which has seen considerable advances in recent years, child psychotherapy continues to lag behind. What research there is tends to be encouraging - for example, there have been two meta-analytic reviews of the field that have each shown that child psychotherapy is associated with modest changes for the better. ${ }^{14}{ }^{15}$ The problem is that they are based on basic research of variable and sometimes doubtful quality. The better studies, covering a variety of diagnostic groups treated in different settings, ${ }^{16}{ }^{17}$ also show positive results, and indeed there is a trend for the better studies to demonstrate greater effectiveness. Family therapy too has shown promise in the 
management of antisocial problems, ${ }^{18}$ child abuse, ${ }^{19}$ anorexia nervosa, ${ }^{20}$ and asthma. ${ }^{21}$

Recording of interviews and the rating of quality was the subject of extensive research in the 1950s and 1960 s by Rogers and his school. ${ }^{22}$ They found that there were qualities of the therapist that seemed to predict good outcome. The most consistent were emotional warmth and accurate empathy. More recently and specifically in the school setting, openness and assertiveness have been shown to be important. ${ }^{17}$

Treatment with psychoactive drugs forms a much smaller but nevertheless important part of practice. ${ }^{23}$ The main drugs used are methylphenidate, which has been shown to improve attention span and disruptive behaviour in hyperactive children, antidepressant drugs, where trials in children have so far failed to show clinical therapeutic effects, and in tics and Tourette's syndrome neuroleptics are effective. Drugs should be given in the context of a total plan of management, including psychological approaches.

(B) THE EFFECTIVENESS OF A PARTICULAR SERVICE The principle here should be to assess whether reputable treatment is being carried out under the best possible conditions: this is where process and outcome measures come together. The question of whether correct principles are being applied in the delivery of psychological interventions is an extremely difficult one. Direct supervision (see above) is one possibility. For some treatments the treatment programme is set out in a manual with suggested stages in the intervention. ${ }^{24}$ This package can then be evaluated in rigorous clinical trials and then applied in practice. There has been some progress in this respect but application in ordinary clinics with limited resources is extremely difficult, if not impossible. It remains a sad truth that evaluative research does not necessarily guide practice. Clinicians are influenced by their previous training and by the techniques they feel comfortable with. As the amount and quality of evaluative research increases, it will be important to check takeup in clinic practice. At a more practical level, there are some ways forward: nonattendance and drop out rates. High rates don't necessarily reflect the quality of the service, characteristics of the family also exert an influence. They are, of course themselves a cause of inefficiency. Preparation for the initial appointment by telephone or a visit seems a worthwhile investment (RE Waler, unpublished observations). ${ }^{25-27}$

\section{(c) CONSUMER OPINION}

It is easy and most important to assess what the consumers think of the service. There are currently some projects on this topic in progress.

Computers can be seen as the 'US cavalry coming over the hill' or as the final nail in the coffin for a service struggling with inadequate resources and impossible demands. The truth is probably somewhere in between and some progress has been made. Two computer software systems have been developed for child psychiatry services ${ }^{28} 29$ together with some interesting attempts at application. ${ }^{30} 31$

In conclusion it can be seen from this brief review that the official introduction of audit has implications for child and adolescent psychiatry, which apply also to many other branches of paediatrics. It may be worth bearing this in mind in the months and years to come.

1 Royal College of Psychiatrists. Preliminary report on medical audit. Psychiatric Bulletin of the Royal College of Psychiatrists 1989;13:577-80.

2 North East Thames Child and Adolescent Psychiatric Advisory Sub-committee. Consultant manpower in child psychiatry. Psychiatric Bulletin of the Royal College of Psychiatrists 1989;13:30-1.

3 Quam L. NHS review: improving clinical effectiveness in the NHS: an alternative to the white paper. $B M \mathcal{F} 1989 ; 299$ : 448-50.

4 Rutter $M$. Child psychiatric disorders in ICD-10. 7 Child Psychol Psychiatry 1989;30:499-513.

5 American Psychiatric Association. Diagnostic and statistical manual for mental disorders. 3rd Ed, revised. (DSM 111-R.) manual for mental disorders. 3rd Ed, revised. (DSM 111-R.)

6 Muslin HL, Thurnblad RJ, Meschel G. The fate of the clinical interview: an observational study. Am $\mathcal{F}$ Psychiatry 1981;138:825-33.

7 Guy Edwards J, Nunn CMH. Three years medical audit in a psychiatric unit. Bulletin of the Royal College of Psychiatrists 1987;11:154-5.

8 Nicol AR. Performance indicators in child and adolescent psychiatry. Psychiatric Bulletin of the Royal College of Psychiatrists 1989;13:94-7.

9 Joint Committee for Higher Psychiatric Training. Handbook. London: Joint Committee for Higher Psychiatric Training, 1990

10 Association of University Teachers of Psychiatry. Undergraduate teaching in child psychiatry. London: Association of graduate teaching in child psychiatry. London:
University Teachers of Psychiatry, 1985.

11 Korner E, chair. First report of the steering group on health service information. London: HMSO, 1982.

12 Committee on Child Health Services. Fit for the future. London: HMSO, 1976. (Court report.) (Cmnd 6680.)

13 Shepherd M, Oppenheim B, Mitchell S. Child behaviour and mental health. London: University of London Press, 1971.

14 Casey RJ. The outcome of psychotherapy with children. Psychol. Bull 1985;98:388-400.

15 Weitz JR, Weiss B, Alicke MD, Klotz ML. Effectiveness of psychotherapy with children and adolescents: a metaanalysis for clinicians. $\mathcal{F}$ Consult Clin Psychol 1987;55: 542-9.

16 Feldman RA, Caplinger TE, Wodarski JS. The St Louis conundrum: the effective treatment of antisocial youths. Englewood Cliffs: Prentice-Hall, 1983.

17 Kolvin I, Garside RF, Nicol AR, Macmillan A, Wolstenholm $\mathrm{F}$, Leitch I. Help starts here: the maladjusted child in ordinary school. London: Tavistock, 1981.

18 Patterson GR, Fleichmann MJ. Maintenance of treatment effects: some consideration concerning family systems and follow up data. Behaviour Therapy 1979;10:168-85.

19 Nicol AR, Smith J, Kay B, Hall D, Barlow J, Williams B. A focused casework approach to the treatment of child abuse: a controlled comparison. $\mathcal{F}$ Child Psychol Psychiatry abuse: a controlled

20 Russell GFM, Szmukler GL, Dare C, Eisler I. An evaluation of family therapy in anorexia nervosa and bulimia nervosa. of family therapy in anorexia nervosa and

21 Lask B, Mathew D. Childhood asthma. A controlled trial of family therapy. Arch Dis Child 1979;54:116-9.

22 Truax CB, Carkhuff RR. Towards effective counseling and psychotherapy. Chicago: Aldine, 1967.

23 Taylor E. Psychopharmacology in childhood. Newsletter of the Association of Child Psychology and Psychiatry 1988;10: 3-6.

24 Kendall PC, Braswell L. Cognitive-behavioural therapy for impulsive children. New York: Guilford Press, 1985

25 Brockless J. The effects of telephone contact/prompting on subsequent attendance at initial appointments at a hospital department of child and adolescent psychiatry. Newsletter of the Association of Child Psychology and Psychiatry 1990; 12:5-8.

26 Skuse D. Attitudes to the psychiatric outpatient clinic. $B M F$ 1975;3:469-76.

27 Cottrell D, Hill P, Walk D, Dearnaley J, Ierotheou A. Factors influencing non-attendance at child psychiatry outpatient appointments. Br F Psychiatry 1988;152:201-4. ein E. Computer systems in clinic management and research. In: Harris-Hendricks J, Black $M$, eds. Child psychiatry: into the 1990s. London: Royal College of Psychiatrists, 1990.

29 Berger M. Installing micros in clinics: options and essentials. In: Berger M, ed. Clinical services: monitoring, evaluation and microcomputers. London: Association of Child Psychology and Psychiatry, 1989. (Occasiona papers No 1.)

30 Byrne $P$. Where angels fear to tread: introducing a o a child guidance clinic. In: Berger $M$, ed. Clinical services: monitoring, evaluation and microscomputers. London: Association of Child Psychology and Psychiatry, 1989. (Occasional papers No 1.)

31 Thompson $M$. Developing a data collection system for a child guidance clinic. In: Berger M, ed. Clinical services: monitoring, evaluation and microcomputers. London: Association of Child Psychology and Psychiatry, 1989. (Occasional papers No 1.) 